\title{
Retraction notice to: "Sharpening of ceramic knife-edges and production of plasma for cutting tools nitriding with the use of a broad fast molecule beam"
}

Refers to

RETRACTED: Sharpening of ceramic knife-edges and production of plasma for cutting tools nitriding with the use of a broad fast molecule beam, Alexander S. Metel, Mechanics \& Industry, Volume 17, Number 7, 2016, published online on 23 December 2016

DOI: $10.1051 / \mathrm{meca} / 2016069$

\begin{abstract}
At the request of the Author, the following article has been retracted. It has come to the attention of the journal and EDP Sciences that a similar version of the article has been previously published in another journal. The Editorial Board of Mechanics \& Industry and EDP Sciences have agreed to retract the article (please see 'Policies for publication of errata and for article retraction at http:// www.mechanics-industry.org/about-the-journal/ethical-standards) at the request of the author as explained here below.
\end{abstract}

Dear Editorial board,

It has come to my attention that the paper authored by Prof. Dr. A.S. Metel and published in the Journal Mechanics \& Industry in December 2016 [1] contains large portions of the text from another his article [2], published in 2011. In fact, the article [1] was aimed to extend the absolutely new and never published results obtained in the article [2]. In the article [2], the authors study parameters of nitrogen plasma and discuss absolutely new results related to the plasma production by fast neutral molecule beam. During the experiments the effect of cutting tools sharpening after treatment was seemingly revealed. This effect was further researched and reliably proved by the author, when in 2016 Prof. Dr. A.S. Metel applied this idea to ceramic cutting tools.

During the period of new data collecting for publishing a new article, with the purpose to publish as fast as possible absolutely new and outstanding results, Prof. Dr. A.S. Metel used for the new article the description of the experimental setup and parameters for plasma from already published article as the data were similar in the large part of it. It was done by experienced author without recognition that majority of new article was based on the previous already published text.

On the stage of correction of the prove, Prof. Dr. A.S. Metel did not take appropriate attention to the quality of the text related to the description of the experimental setup and plasma and concentrated himself more on accuracy of the obtained physical parameters as he understood it was the most important part of his new work.

When the article was already published, it was recognized as self-plagiarism by Prof. Dr. A.S. Metel, but it was not his intention.

The author kindly asks the editors of the Journal Mechanics \& Industry to retract the published article from international bibliographic data bases.

The author regrets and apologizes to the editors of the Journal Mechanics \& Industry and to the international research community. 


\section{References}

[1] Alexander S. Metel, Sharpening of ceramic knife-edges and production of plasma for cutting tools nitriding with the use of a broad fast molecule beam, Mechanics \& Industry 17 (2016) 703

[2] Alexander Metel, Sergei Grigoriev, Yury Melnik, Vitaly Panin and Vladimir Prudnikov, Cutting Tools Nitriding in Plasma Produced by a Fast Neutral Molecule Beam, Japanese Journal of Applied Physics 50(8S1) 2011

Alexander Metel 